University of Nebraska - Lincoln

DigitalCommons@University of Nebraska - Lincoln

Sociology Department, Faculty Publications

Sociology, Department of

2010

\title{
Bidirectional, Unidirectional, and Nonviolence: A Comparison of the Predictors Among Partnered Young Adults
}

\author{
Lisa A. Melander \\ Kansas State University, Imeland@ksu.edu \\ HarmoniJoie Noel \\ University of Nebraska-Lincoln, hnoel@nebraska.edu \\ Kimberly A. Tyler \\ University of Nebraska-Lincoln, kim@ktresearch.net
}

Follow this and additional works at: https://digitalcommons.unl.edu/sociologyfacpub

Part of the Sociology Commons

Melander, Lisa A.; Noel, HarmoniJoie; and Tyler, Kimberly A., "Bidirectional, Unidirectional, and Nonviolence: A Comparison of the Predictors Among Partnered Young Adults" (2010). Sociology Department, Faculty Publications. 128.

https://digitalcommons.unl.edu/sociologyfacpub/128

This Article is brought to you for free and open access by the Sociology, Department of at DigitalCommons@University of Nebraska - Lincoln. It has been accepted for inclusion in Sociology Department, Faculty Publications by an authorized administrator of DigitalCommons@University of Nebraska - Lincoln. 


\title{
Bidirectional, Unidirectional, and Nonviolence: A Comparison of the Predictors Among Partnered Young Adults
}

\author{
Lisa A. Melander, PhD \\ Kansas State University \\ HarmoniJoie Noel, PhD \\ Kimberly A. Tyler, PhD \\ University of Nebraska-Lincoln
}

Corresponding author - Lisa A. Melander, PhD, Kansas State University, Department of Sociology, Anthropology, and Social Work, 204 Waters Hall, Manhattan, KS 66506; email lmeland@k-state.edu

\begin{abstract}
In order to understand more fully the context and impact of intimate partner violence (IPV), it is important to make distinctions between different types of relationship aggression. As such, the current study longitudinally examines the differential effects of childhood, adolescent, and demographic factors on three different partner violence groups: those who experience bidirectional IPV, those who experience unidirectional IPV, and those who do not experience either form of IPV. Multinomial logistic regression results reveal that depressive symptoms and lower partner education predict bidirectional when compared to unidirectional IPV and nonviolence. In contrast, other risk factors such as illicit drug use are found to be predictors of unidirectional violence only, which reveals that the correlates of violence vary depending upon the type of IPV examined.
\end{abstract}

Keywords: bidirectional partner violence, risk factors, young adults

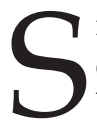
ince its rise to popularity in the 1960s and 1970s during the second wave of the women's movement, topics surrounding various issues of family violence have permeated both scholarly publications and academic discourse in general (Gelles, 1997). Despite the relative continuity of violence topics, the focus of these studies, especially with regard to intimate partner violence (IPV), has changed drastically over the years. For example, the literature regarding "battered woman syndrome" (Walker, 1979, p. 19) was quickly rebutted with concerned discussions of an equally alarming and a possibly more silent epidemic of the "battered husband phenomenon" (Steinmetz, 1977-1978, p. 503). More recently, partner violence researchers have been charged with the task of moving in a new direction, to "make distinctions among types of partner violence" (Johnson \& Ferraro, 2000, p. 948).

To understand the nuances of partner violence research, scholars have broadened the focus of their studies to include various types of violence, considering both males and females as victims and perpetrators of IPV (Anderson, 2002; Caetano, Vaeth, \& Ramisetty-Mikler, 2008; Prospero, 2008; Williams \& Frieze, 2005). One of the more recent trends in the family violence literature focuses around examining the prevalence and predictors of bidirectional violence, ${ }^{1}$ 
which generally refers to situations in which a respondent reports being both a victim and perpetrator of violence in the context of an intimate relationship (Caetano, Ramisetty-Mikler, \& Field, 2005; Harned, 2002; Lewis, Travea, \& Fremouw, 2002; Robertson \& Murachver, 2007; Straus, 2008; Tyler, Melander, \& Noel, 2009). Because few studies have employed measures of bidirectional IPV, little is known about the predictors that are specific to this form of violent behavior and how they compare to individuals involved in unidirectionally violent relationships (i.e., only one partner perpetrates violence) and nonviolent couples. Consequently, the purpose of this article is to examine whether childhood, adolescent, and demographic predictors differ across three partner violence groups: those who experience bidirectional partner violence, those who experience unidirectional violence, and those who do not experience either form of violence. Identifying the risk factors associated with both bidirectional and unidirectional violence will not only provide guidance for future research endeavors but may also assist clinicians with designing appropriate treatment and intervention strategies.

\section{LITERATURE REVIEW}

\section{Child Maltreatment}

Because the family is often considered society's most violent institution, it is important to look at the different forms of family violence simultaneously (Gelles, 1997). One of the most consistent predictors of partner violence is a history of child abuse. Physical abuse, sexual abuse, and neglect have been found to predict partner violence perpetration and victimization (Field \& Caetano, 2005; Tyler et al., 2009; Whitfield, Anda, Dube, \& Felitti, 2003). As such, individuals who experience maltreatment within the family of origin may be vulnerable to revictimization at the hands of an intimate partner.

\section{Depressive Symptomology}

Although previous research has found that those in violent intimate relationships are more likely to have depressive symptoms in the aftermath of their IPV experiences (Anderson, 2002; Prospero, 2008; Zlotnick, Johnson, \& Kohn, 2006), other studies have explored whether depressive symptoms occur prior to the violent interactions (Keenan-Miller, Hammen, \& Brennan, 2007). For example, Lipsky, Caetano, Field, and Bazargan (2005) found that depressive symptoms predicted both IPV perpetration and victimization. In contrast, Caetano and colleagues (2008) found that rates of depression did not significantly differ among their perpetrator only, victim only, and mutual violence couples. Because of these contradictory findings it is important to consider whether depressive symptomology is a precursor to different types of IPV experiences.

\section{Substance Use}

Substance use has also been linked to IPV in both general population and clinical samples (Caetano et al., 2005; Drapkin, McCrady, Swingle, \& Epstein, 2005; Lipsky et al., 2005). Although some researchers find no differences between mutually violent and perpetrator or victim-only couples in terms of alcohol use (Caetano et al., 2008; Lewis et al., 2002), others report that drinking is a risk factor for bidirectional violence. Males and females who reported binge drinking in the past month were at an increased risk for mutual IPV among a national sample of cohabiting and married adults (Cunradi, 2007). El-Bassel, Wu, Go, and Hill (2005) found that although frequent crack and marijuana use increased the likelihood of 
subsequent physical and sexual IPV, the findings were inconclusive for cocaine, heroin, and frequent binge drinking. In other words, these findings indicate that the relationship between frequent drug use and bidirectional IPV may vary by type of drug.

\section{Relationship Status}

Relationship status has an impact on being involved in a violent relationship, with cohabiters having the highest rates of violence followed by married and dating couples (Magdol, Moffitt, Caspi, \& Silva, 1998; Stets \& Straus, 1990). Brown and Bulanda (2008) examined the association between relationship status and IPV perpetration and victimization, and found that cohabiting women were the most likely to perpetrate or be the victims of IPV followed by married and dating women, respectively. For men, those in dating relationships were least likely to perpetrate or be victimized by IPV; cohabiting and married men did not significantly differ in their rates of perpetration or victimization. As such, accounting for relationship status may be an important factor for bidirectional violence.

\section{Demographic Characteristics}

There have been mixed findings with regard to whether males or females are more likely to be perpetrators and/or victims of partner violence. Several researchers have found that females are victimized more often by an intimate partner than their male counterparts (Catalano, 2007; Gover, Kaukinen, \& Fox, 2008). According to Rennison and Welchans (2000), women are victimized by intimates at approximately five times the rate of men. Others (Capaldi \& Owen, 2001; Williams \& Frieze, 2005), however, report that women victimize men more often. For example, in their nationally representative sample of adolescents, Whitaker, Haileyesus, Swahn, and Saltzman (2007) found that women reported more partner violence perpetration and victimization than men. Alternatively, some researchers find that men and women use approximately equal levels of violence toward one another and report similar levels of victimization (Anderson, 2002; Harned, 2002; Robertson \& Murachver, 2007; Straus, 2008). Cunradi (2007), for example, found that approximately the same proportion of men $(3.1 \%)$ and women (3.2\%) reported experiencing mutual IPV.

Other demographic factors that have been linked to IPV perpetration and victimization include age, racial and ethnic background, and sociodemographic status. In general, younger individuals are at higher risk for both perpetrating and becoming victims of IPV (Anderson, 2002; Cunradi, 2007; Gelles, 1997; Prospero, 2008) with females aged 20 to 24 having the highest risk of nonfatal IPV (Catalano, 2007). In terms of race and ethnicity, Field and Caetano (2005) found that African American and Hispanic couples reported higher frequencies of mutual physical partner violence than their White counterparts. Similarly, Weston, Temple, and Marshall (2005) found that African American women in mutually violent relationships experienced significantly more sexual and physical violence than their Euro-American and Mexican American counterparts. Finally, those with lower socioeconomic attainment, as measured by the educational level of the respondents (Drapkin et al., 2005; Frias \& Angel, 2005), their parents (Foshee et al., 2008), or their partners (Brown \& Bulanda, 2008), are at increased risk for partner violence.

\section{THEORETICAL PERSPECTIVE: JOHNSON'S IPV TYPOLOGY}

Johnson $(1995,2006)$ created a typology of violent couples that has been used by other social science researchers to provide context to contradictory findings in the dating violence litera- 
ture (Anderson, 2002; Prospero, 2008). In a series of articles beginning in the 1990s, Johnson has revised and expanded his typology of violence, which is based on the degrees of control and violence that are present in the relationship to include the following categories: intimate terrorism, mutual violent control, violent resistance, and situational couple violence. Previously referred to as patriarchal terrorism, intimate terrorism refers to a form of "terroristic control" whereby one partner systematically uses violence as well as a broad range of other power and control tactics (Johnson, 1995, p. 284). In this way, intimate terrorism can be understood as a general attempt to control an intimate partner by any means necessary and is more likely to escalate over time compared to other forms of violence (Johnson \& Ferraro, 2000; Johnson \& Leone, 2005). Although little is known about this rare form of violence (Johnson \& Ferraro, 2000), mutual violent control occurs when both partners are violent and controlling toward each other. Violent resistance, on the other hand, occurs when one partner is violent and controlling and the other partner responds with violence in a manner akin to self-defense. Finally, situational couple violence, which was previously referred to as common couple violence (Johnson, 1995), occurs when either one or both partners are violent but is not typically connected to a general pattern of control (Johnson, 2006; Johnson \& Ferraro, 2000). This form of aggression usually occurs in the context of a particular situation in which conflict occasionally "gets out of hand" and rarely escalates to severe, life-threatening violence (Johnson, 1995, p. 285). Although some researchers have not found support for using these categories of relationship violence (Anderson, 2008), this typology postulates that there are important differences between unidirectional and bidirectional violence. As such, it is important to learn more about these distinct forms of aggression to inform prevention and intervention efforts.

\section{THE CURRENT STUDY}

Despite the relatively large body of literature on IPV, there have been few studies that have simultaneously addressed the relationship between child maltreatment experiences, internalizing behaviors, and personal characteristics and bidirectional violence. Furthermore, researchers have not determined whether the predictors of IPV vary across different partner violence groups. As such, it is largely unknown whether factors that are usually linked to unidirectional violence are also associated with bidirectional IPV. Existing studies also generally utilize cross-sectional data, which makes it difficult to establish temporal order. The current study addresses each of these shortcomings by examining the following research question using a nationally representative, longitudinal sample: Do childhood, adolescent, and demographic factors (e.g., child abuse, substance use, and relationship status) vary between bidirectional, unidirectional, and nonviolent relationships in young adulthood?

\section{METHOD}

\section{Data}

The analyses are based on Waves I and III of the National Longitudinal Study of Adolescent Health (Add Health). The data are from the restricted access core sample of over 15,000 individuals who were first interviewed in grades 7 through 12 and then completed a Wave III in-home interview in young adulthood (18-27 years old; see Udry, 1997 for a more detailed description of the methodological structure of this data set). The analytic sample was re- 
stricted to the 6,563 Wave III respondents who reported having one current romantic partner and had valid data on the variables of interest. All of the independent variables were measured at Wave I, with the exception of the child maltreatment items, which were asked retrospectively during the Wave III interview.

\section{Measures}

Dependent Variable. Intimate Partner Violence was a nominal variable with four categories: bidirectional violence, perpetration only, victimization only, and no violence based on two questions from both a victim and perpetrator perspective during Wave III. The perpetration questions asked the respondent how often in the past year they (a) threatened their partner with violence, pushed, shoved, or threw something at their partner that could hurt, and (b) slapped, hit, or kicked their partner. These items were combined and dichotomized such that $0=$ no perpetration in the past year and $1=$ at least one incident of perpetration in the past year. For victimization, respondents were asked two questions about the same behaviors that were in the perpetration items with the exception that the introduction to the questions asked how often their partner did the following things to them (i.e., inflict violence). Respondents who reported both physical perpetration and victimization in the past year were classified as bidirectional. Those who reported only perpetration were categorized as perpetration only, whereas respondents who reported only victimization were categorized as victimization only. The nonviolent group consisted of people who did not report any violence in the past year.

Independent Variables. The childhood abuse measures are modified versions of questions administered in previous surveys, such as the Revised Conflict Tactics Scale. Childhood physical abuse was a continuous variable based on the question, "By the time you started 6th grade, how often had your parents or other adult caregivers slapped, hit, or kicked you?" Responses ranged from $0=$ never to $5=$ more than 10 times $(M=.76$; $S D=$ 1.46). This variable was transformed using a square root to reduce positive skew. Childhood sexual abuse was measured by the question, "By the time you started 6th grade, how often had one of your parents or other adult caregivers touched you in a sexual way, forced you to touch him or her in a sexual way, or forced you to have sexual relations?" A dichotomous variable was created where $0=$ no sexual abuse and $1=$ at least one childhood sexual abuse experience. Childhood neglect was measured by asking two questions, "By the time you started 6th grade, how often had your parents or other adult caregivers (a) not taken care of your basic needs, such as keeping you clean or providing food or clothing and (b) left you home alone when an adult should have been with you?" Responses for each question ranged from $0=$ never to $5=$ more than 10 times. These items, ranging from 0 to 10 , were summed into a scale-and then transformed using a square root to adjust for positive skew $(M=1.27 ; S D=2.00)$.

Depressive symptoms consisted of 15 items from the Center for Epidemiological Studies Depression Scale (CES-D; Radloff, 1977). The CES-D requires respondents to reflect upon their experiences during the week prior, to the interview and includes items such as "I felt that I could not shake off the blues, even with help from my family and my friends" and "I was bothered by things that don't usually bother me." Responses ranged from 0 (never) to 3 (most of the time or all the time). Positive items were reverse coded so that higher scores indicated more depressive symptomology $(\alpha=.85)$. The scale ranged from 0 to $42(M=9.06 ; S D$ $=6.32$ ) and was logged to account for positive skew.

Three substance use items were included in the analyses. Alcohol use was a single item that asked: "During the past 12 months, on how many days did you drink alcohol?" Re- 
sponse categories included $0=$ none, $1=1$ or 2 days, $2=$ once $a$ month or less, $3=2$ or 3 days a month, $4=1$ or 2 days a week, $5=3$ to 5 days a week, and $6=$ every day or almost every day $(M=$ 1.16 ; $S D=1.44)$. Marijuana use was measured by asking respondents: "During the past 30 days, how many times did you use marijuana?" This variable was logged to account for the high positive skew $(M=1.76$; $S D=14.53)$. Illicit drug use was a single item that asked respondents how often they used the following drugs in the past 30 days: cocaine; inhalants; any other type of illegal drug such as LSD, PCP, ecstasy, mushrooms, speed, ice, heroin, or pills without a doctor's prescription, or an illegal drug using a needle. This item was dichotomized into $0=$ did not use in past 30 days and $1=$ used at least one form of an illicit drug at least once in the past 30 days.

Relationship status was measured by three dichotomous variables indicating whether the partners are currently married, cohabitating, or dating.

Demographic Characteristics. Female is a dichotomous-variable where $0=$ male and 1 = female. Respondent age measures the respondent's current age with a range from 18 to 27 years. Respondent race was measured by five dichotomous variables representing White, Black, Hispanic, Asian, and Native American/Other. Respondent education included four categories that capture the highest level of education completed. Partner education measured the respondent's partner's highest level of education as reported by the respondent. Parent education was a measure of the educational attainment of the respondent's most educated parent. All of the education variables (e.g., respondent, partner, and parent) included the following categories: less than high school degree, high school degree, some college, and 4-year college degree or more. Reports were taken from the parent survey unless there were missing data and then the respondent's report of their parent's education was used.

\section{RESULTS}

\section{Univariate}

Fifty-seven percent of the sample was female and the average respondent age was 22 years. The majority of the sample was White (72\%) followed by $13 \%$ Black, $7 \%$ Hispanic, $4 \%$ Native American/Other, and 3\% Asian. In terms of educational attainment, $14 \%$ of the sample had less than a high school education, 32\% had a high school degree, $38 \%$ completed some college, and $15 \%$ had a 4 -year college degree or above. Almost half of the respondents $(48.6 \%)$ were dating, $26 \%$ were cohabiting, and $25 \%$ were married. Overall, $26 \%$ of the sample experienced physical child abuse, $4 \%$ were sexually abused, and $38 \%$ indicated that they had been neglected on at least one occasion. Twenty-five percent of respondents experienced IPV, with $13 \%$ reporting bidirectional violence, $7 \%$ reporting perpetration only, and $5 \%$ reporting victimization only.

\section{Multivariate}

Multinomial logistic regression (MLR) was performed using SAS to predict the probability of being in relationships with different IPV experiences. MLR, which is an extension of standard logistic regression analysis, includes more than two categories in the dependent variable. One group is selected as the reference group (e.g., no violence), and each of the remaining groups is compared to the reference group in separate logistic regression models 
that are estimated simultaneously (DeMaris, 1992). In Table 1, nonviolence is compared to (a) bidirectional violence in columns 1 and 2, (b) perpetration only in columns 3 and 4, and (c) victimization only in columns 5 and 6 . Bidirectional violence is compared to perpetration only in columns 7 and 8 and victimization only in columns 9 and 10 .

Childhood physical abuse is a risk factor for bidirectional violence and perpetration only when compared to no violence, $\operatorname{Exp}(B)=1.36$ and $\operatorname{Exp}(B)=1.23$, respectively. Individuals with childhood sexual abuse histories were also at increased risk for bidirectional compared to no violence, $\operatorname{Exp}(B)=1.71$, and neglect is a risk factor for victimization only compared to no violence, $\operatorname{Exp}(B)=1.16$. There were differences for mental health and substance use: people with higher depressive symptoms were almost twice as likely to be in a bidirectionally violent relationship compared to a nonviolent, relationship $\operatorname{Exp}(B)=1.97$. Although frequency of alcohol consumption was not associated with a greater risk for violence of any type compared to no violence, for people who were in a violent relationship, alcohol use was associated with bidirectional violence rather than perpetration only, $\operatorname{Exp}(B)=1.19$. Additionally, people who have used illicit drugs in the past month were more than twice as likely to be perpetrators only compared to those in nonviolent relationships, $\operatorname{Exp}(B)=2.40$.

In terms of relationship status, people who are dating compared to cohabitating were less likely to experience any type of violence, including bidirectional, perpetrator only, or victim only, $\operatorname{Exp}(B)=.43, \operatorname{Exp}(B)=.48$, and $\operatorname{Exp}(B)=.52$, respectively. Gender was the most consistent predictor across all models. For example, females are less likely to experience bidirectional violence compared to perpetration only and more likely to experience bidirectional violence than victimization only, $\operatorname{Exp}(B)=.22$ and $\operatorname{Exp}(B)=3.67$, respectively. Although age is a protective factor against both bidirectional violence, $\operatorname{Exp}(B)=.88$, and perpetration only, $\operatorname{Exp}(B)=.92$, compared to no violence, it may be a risk factor for victimization: When older individuals are in a violent relationship, they are less likely to experience bidirectional violence compared to victimization only, $\operatorname{Exp}(\mathrm{B})=.89$.

With regard to race, Blacks are consistently more likely to be in a violent relationship of any type compared to a nonviolent relationship. For example, Blacks were almost two and a half times more likely to be in a bidirectionally violent relationship compared to a nonviolent relationship, $\operatorname{Exp}(B)=2.46$. Asians and people who were classified as Native American/Other were more likely than Whites to report being in a bidirectionally violent relationship compared to a nonviolent relationship, $\operatorname{Exp}(B)=1.48$ and $\operatorname{Exp}(B)=2.09$, respectively.

In terms of education, respondents with some college experience were more likely to report victimization compared to no violence, $\operatorname{Exp}(B)=1.66$, and were less likely to report bidirectional violence compared to victimization only, $\operatorname{Exp}(B)=.62$. Alternatively, respondents with 4 or more years of college were less likely to report victimization only compared to no violence, $\operatorname{Exp}(B)=.35$, but more likely to report bidirectional violence compared to victimization only, $\operatorname{Exp}(B)=3.07$. Partner's education was also associated with different forms of IPV. For instance, those who had partners with less than a high school degree were more than twice as likely to experience bidirectional violence compared to no violence, $\operatorname{Exp}(B)=2.30$, and perpetration only, $\operatorname{Exp}(B)=2.05$, than those with a high school diploma. Compared to their high school counterparts, having a partner with 4 or more years of college was a protective factor against both bidirectional, $\operatorname{Exp}(B)=.29$, and perpetration only, $\operatorname{Exp}(B)=.44$, when compared to no violence. When those with 4 or more years of college education were in a violent relationship, they were less likely to be involved in bidirectional violence compared to victimization only, $\operatorname{Exp}(B)=.31$. 


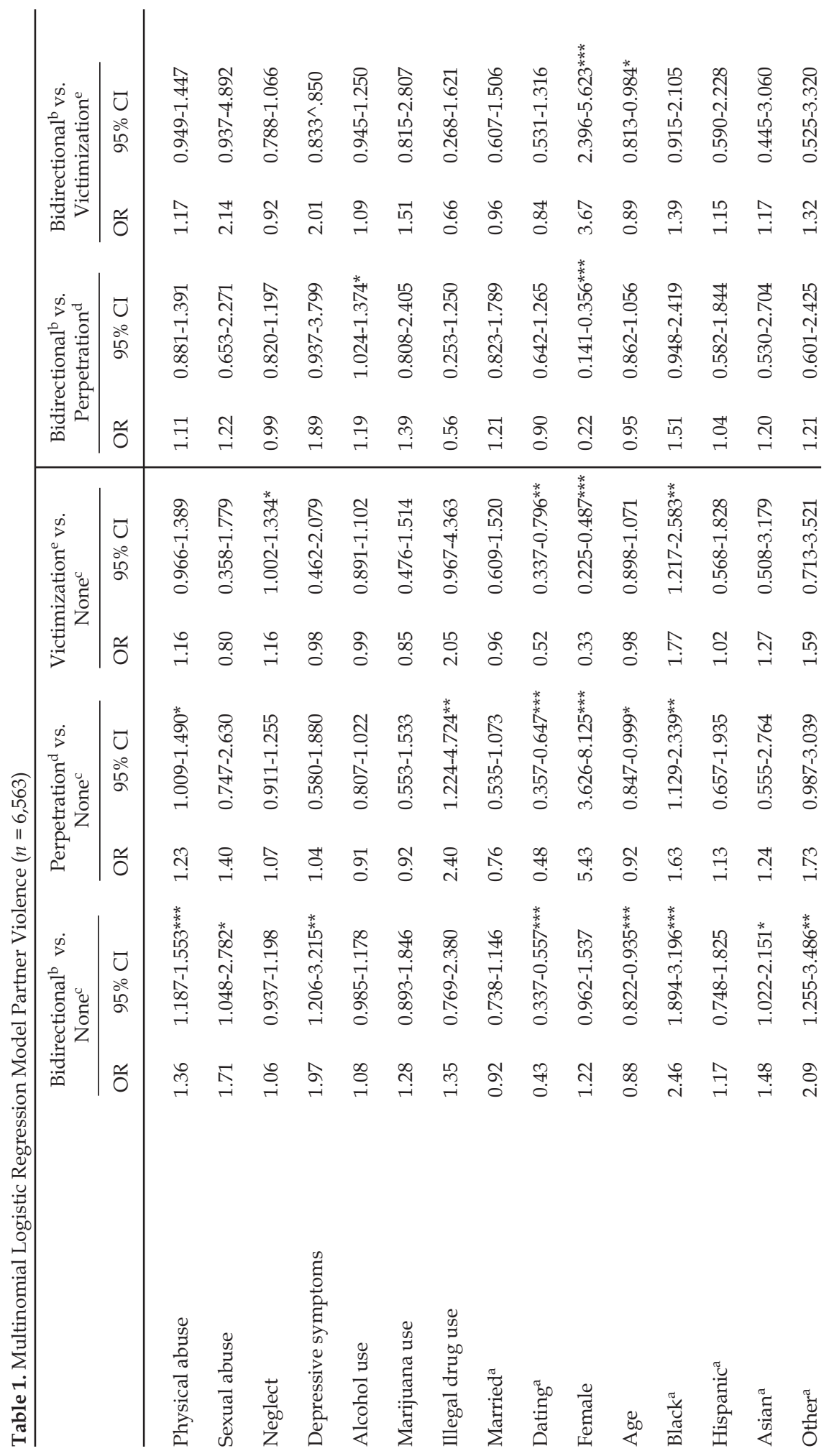









\section{DISCUSSION}

The current study set out to empirically test whether the childhood and adolescent risk factors and demographic characteristics that are commonly associated with partner violence, such as depressive symptoms and gender, vary between bidirectional, unidirectional, and nonviolent relationships. Overall, $13 \%$ of the young adults in this study reported bidirectional violence and $12 \%$ experienced unidirectional aggression with $7 \%$ reporting perpetration only and 5\% reporting victimization only within a current relationship, all of which place them at greater risk of continued partner violence throughout their adulthood. The multinomial logistic regression results also reveal that important differences exist between the different relationship violence categories in terms of child abuse histories, depressive symptomology, substance use, relationship status, and demographic characteristics.

Consistent with previous research (Field \& Caetano, 2005; Whitfield et al., 2003), those who have experienced childhood physical abuse are at higher risk for bidirectional violence and perpetration only, and victims of childhood sexual abuse are at higher risk for bidirectional violence when compared to nonviolent relationships. Additionally, those who have experienced childhood neglect are at an increased risk for victimization only compared to nonviolence. It is possible that young adults who experienced childhood maltreatment learn that this type of behavior is an acceptable and appropriate way to interact with people they love and thus are more likely to be violent within their own intimate relationships and/or be more accepting when it occurs. The current study also reveals that depressive symptoms are another risk factor for IPV, which is consistent with the work of others (cf. Keenan-Miller et al., 2007; Lipsky et al., 2005). That is, those with higher levels of depressive symptoms are more likely to be in bidirectionally violent relationships compared to their nonviolent counterparts. This finding is consistent with previous research that has found that individuals who have a history of depression are more likely to have intimate relationships characterized by high levels of discord (Gotlib, Lewinsohn, \& Seeley, 1998; O'Leary, Christian, \& Mendell, 1994) which may contribute to an increase in violent altercations. Finally, although individuals who drink more alcohol are at higher risk for being in bidirectionally violent compared to perpetration-only relationships, illicit drug users are more likely to engage in perpetration only than no violence. This relationship may perhaps be attributed to the view of substance use as a social disinhibitor or a rationalization for violence (Flanzer, 2005) but because we do not know whether these controlled substances were used during the violent incidents, these findings should be interpreted with caution.

Relationship status and demographic factors are also associated with the different forms of violence. Compared to those in cohabiting relationships, dating couples are less likely to experience bidirectional, perpetration only, and victimization only compared to no violence. As such, cohabiters are at higher risk for partner violence when compared to individuals in dating relationships which is consistent with previous research (Magdol et al., 1998; Stets \& Straus, 1990). Cohabiting couples may be at higher risk for IPV due to more isolation from social network members and lower relationship investment and/or commitment (Johnson \& Ferraro, 2000; Stets \& Straus, 1990). Gender is also associated with the different partner violence categories: Females are more likely to be perpetrators only and less likely to be victims only when compared to nonviolent relationships. When in violent relationships, females are less likely to be in bidirectionally violent compared to perpetration-only relationships and more likely to be in bidirectionally violent compared to victimization-only relationships. These results are consistent with previous research that finds that women are more likely to be the perpetrators of IPV than men (Capaldi \& Owen, 2001; Whitaker et al., 
2007; Williams \& Frieze, 2005). Furthermore, these findings could be attributed to the contention that women may be more willing to admit to using violence compared to males, as men may be afraid of the negative stigma associated with victimizing a woman (Gover et al., 2008). Finally, age is a protective factor against relationship violence, as the odds of bidirectional violence and perpetration only compared to no violence are reduced with age, which is perhaps because individuals acquire more effective conflict resolution skills as they mature.

Different types of IPV are also associated with certain racial/ethnic and educational groups. Consistent with previous research (Caetano et al., 2005; Weston et al., 2005), there are some differences in the type of partner violence experienced among racial and ethnic groups. When compared to White individuals, those who are Black, Asian, or Native American/Other are more likely to be in bidirectionally violent compared to nonviolent relationships. Additionally, Black individuals are more likely than Whites to report being perpetrators or victims only compared to nonviolent relationships. These differences may reflect varied experiences of IPV and/or the propensity for respondents from these divergent racial and ethnic groups to perceive and report their partner's and own behavior as abusive (Frias \& Angel, 2005). It is difficult, however, to make any substantive interpretations of these findings regarding race given the racial and ethnic heterogeneity of the people within the "Asian" category (i.e., Korean and Japanese), for example. Although parent education is not associated with IPV, respondent education was differentially associated with partner violence. For example, when in a violent relationship, respondents with some college experience were less likely to report bidirectional violence whereas those with 4 or more years of college were more likely to report bidirectional violence when compared to those reporting victimization only. Partner education is also linked to aggression: Having a partner with less than a high school education is associated with bidirectional violence compared to nonviolence and perpetration only, whereas being in a relationship with a partner with 4 or more years of college was a protective factor from both bidirectional violence and perpetration only compared to no violence. Individuals with lower educational attainment are more likely to perpetrate IPV (Drapkin et al., 2005; Stets \& Straus, 1990) and if one or both partners have lower educational levels, this will perhaps increase the likelihood of relationship violence.

Overall, the current findings provide some support for Johnson's $(1995,2006)$ contention that there are different types of violence experienced among intimate couples. According to this typology of IPV, the types of violence that are experienced within relationships vary depending upon the degree of violence and control that are present in the relationship. Although the present study could not include direct measures of control or broader measures of violence, there is evidence that some of the predictors of bidirectional violence diverge from those associated with unidirectional aggression. As such, this provides support for the notion that these types of violence are distinct and should be treated separately. Understanding more about the unique predictors of these different types of relationship violence could provide guidance for clinicians designing intervention efforts.

There are some limitations to the present study. First, the data are based on self-reports of both partner violence perpetration and victimization, which may be biased without knowing the partner's report. A second limitation is that the reports of child maltreatment are retrospective and based upon the recall of adult respondents. These reports could be unreliable due to memory loss or an unwillingness to report sensitive experiences (Hussey, Chang, \& Kotch, 2006). Third, Add Health only includes two questions on IPV that combine physical and psychological aggression, which does not distinguish be- 
tween these types of violence or capture the range of abusive incidents that may be experienced such as stalking. Furthermore, respondents were only asked to reflect on IPV that occurred within the past year. As such, the results may be underestimating the actual prevalence of IPV occurring within these intimate relationships. Finally, the sample consists solely of young adults; thus, the findings cannot be generalized to individuals outside this age group.

Notwithstanding these limitations, there are several strengths of this study. First, a longitudinal survey design was used that incorporates data from both males and females. Second, although causality cannot be inferred from the findings, using a large, nationally representative sample allows for both generalizability of results and confidence in the significant differences found. Third, this study makes an important contribution to the body of literature on partner violence by specifically focusing on bidirectional violence and comparing it to both unidirectional and no violence instead of merely combining the violence groups into a single IPV measure or just comparing bidirectional to nonviolence.

Partner violence affects millions of people each year and understanding some of the early life risk factors is important for interventions that could prevent bidirectional violence in adulthood. Based on findings from this study, services related to the treatment of child physical abuse and adolescent controlled substance use and depression are especially needed for the prevention of bidirectional violence in young adulthood. Future research should explore other potential predictors of bidirectional violence, such as the amount of time a respondent reports being in a marital, cohabiting, or dating relationship, and the role of gender among a variety of violent relationships using couple-level data.

\section{NOTE}

1. Many contemporary studies refer to what is defined as bidirectional violence in the literature review with a variety of phrases, including mutual violence. For the purposes of the current study, the authors retained the terminology used by the researchers cited.

\section{REFERENCES}

Anderson, K. L. (2002). Perpetrator or victim? Relationships between intimate partner violence and well-being. Journal of Marriage \& Family, 64, 851-863.

Anderson, K. L. (2008). Is partner violence worse in the context of control? Journal of Marriage $\mathcal{E}$ Family, 70, 1157-1168.

Brown, S. L., \& Bulanda, J. R. (2008). Relationship violence in young adulthood: A comparison of daters, cohabitors, and marrieds. Social Science Research, 37, 73-87.

Caetano, R., Ramisetty-Mikler, S., \& Field, C. A. (2005). Unidirectional and bidirectional intimate partner violence among White, Black, and Hispanic couples in the United States. Violence \& Victims, 20, 393^06.

Caetano, R., Vaeth, P. A., \& Ramisetty-Mikler, S. (2008). Intimate partner violence victim and perpetrator characteristics among couples in the United States. Journal of Family Violence, 23, 507-518.

Capaldi, D., \& Owen, L. D. (2001). Physical aggression in a community sample of at-risk young couples: Gender comparisons for high frequency, injury, and fear. Journal of Family Psychology, 15, 425-440.

Catalano, S. (2007). Intimate partner violence in the United States. Accessed June 10, 2009, at http:// www.ojp.usdoj.gov/bjs/pub/pdf/ipvus.pdf 
Cunradi, C. B. (2007). Drinking level, neighborhood social disorder, and mutual intimate partner violence. Alcoholism: Clinical \& Experimental Research, 31, 1012-1019.

DeMaris, A. (1992). Logit modeling: Practical applications. Newbury Park, CA: Sage.

Drapkin, M. L., McCrady, B. S., Swingle, J. M., \& Epstein, E. E. (2005). Exploring bidirectional couple violence in a clinical sample of female alcoholics. Journal of Studies on Alcohol, 66, 213-219.

El-Bassel, N., Gilbert, L., Wu, E., Go, H., \& Hill, J. (2005). Relationship between drug abuse and intimate partner violence: A longitudinal study among women receiving methadone. American Journal of Public Health, 95, 465-470.

Field, C. A., \& Caetano, R. (2005). Longitudinal model predicting mutual partner violence among White, Black, and Hispanic couples in the United States general population. Violence $\mathcal{E}$ Victims, 20,499-511.

Flanzer, J. P. (2005). Alcohol and other drugs are key causal agents of violence. In D. R. Loseke, R. J. Gelles, \& M. M. Cavanaugh (Eds.), Current controversies on family violence (2nd ed., pp. 163-173). Thousand Oaks, CA: Sage.

Foshee, V. A., Karriker-Jaffe, K. J., Reyes, H. L., Ennett, S. T., Suchindran, C., Bauman, K. E., et al. (2008). What accounts for demographic differences in trajectories of adolescent dating violence? An examination of intrapersonal and contextual mediators. Journal of Adolescent Health, 42, 596-604.

Frias, S. M., \& Angel, R. J. (2005). The risk of partner violence among low-income Hispanic subgroups. Journal of Marriage \& Family, 67, 552-564.

Gelles, R. J. (1997). Intimate violence in families (3rd ed.). Thousand Oaks, CA: Sage.

Gotlib, I. H., Lewinsohn, P. M., \& Seeley, J. R. (1998). Consequences of depression during adolescence: Marital status and marital functioning in early adulthood. Journal of Abnormal Psychology, 107, 686-690.

Gover, A. R., Kaukinen, C., \& Fox, K. A. (2008). The relationship between violence in the family of origin and dating violence among college students. Journal of Interpersonal Violence, 23, 1667-1693.

Harned, M. S. (2002). A multivariate analysis of risk markers for dating violence victimization. Journal of Interpersonal Violence, 17, 1179-1197.

Hussey, J. M., Chang, J. J., \& Kotch, J. B. (2006). Child maltreatment in the United States: Prevalence, risk factors, and adolescent health consequences. Pediatrics, 118, 933-942.

Johnson, M. P. (1995). Patriarchal terrorism and common couple violence: Two forms of violence against women. Journal of Marriage \& the Family, 57, 283-294.

Johnson, M. P. (2006). Conflict and control: Gender symmetry and asymmetry in domestic violence. Violence Against Women, 12, 1003-1018.

Johnson, M. P., \& Ferraro, K. J. (2000). Research on domestic violence in the 1990s: Making distinctions. Journal of Marriage \& Family, 62, 948-963.

Johnson, M. P., \& Leone, J. M. (2005). The differential effects of intimate terrorism and situational couple violence: Findings from the National Violence Against Women Survey. Journal of Family Issues, 26, 322-349.

Keenan-Miller, D., Hammen, C., \& Brennan, P. (2007). Adolescent psychosocial risk factors for severe intimate partner violence in young adulthood. Journal of Consulting $\mathcal{E}$ Clinical Psychology, 75,456-463.

Lewis, S. F., Travea, L., \& Fremouw, W. J. (2002). Characteristics of female perpetrators and victims of dating violence. Violence \& Victims, 5, 593-606.

Lipsky, S., Caetano, R., Field, C. A., \& Bazargan, S. (2005). The role of alcohol use and depression in intimate partner violence among Black and Hispanic patients in an urban emergency department. American Journal of Drug \& Alcohol Abuse, 31, 225-242. 
Magdol, L., Moffitt, T. E., Caspi, A., \& Silva, P. A. (1998). Hitting without a license: Testing explanations for differences in partner abuse between young adult daters and cohabitors. Journal of Marriage \& the Family, 60, 41-55.

O'Leary, K. D., Christian, J. L., \& Mendell, N. R. (1994). A closer look at the link between marital discord and depressive symptomatology. Journal of Social \& Clinical Psychology, 13, 33-41.

Prospero, M. (2008). The effect of coercion on aggression and mental health among reciprocally violent couples. Journal of Family Violence, 23, 195-202.

Radloff, L. S. (1977). The CES-D Scale: A self-report depression scale for research in the general population. Applied Psychological Measurement, 1, 385^401.

Rennison, C. M., \& Welchans, S. (2000). Intimate partner violence (Bureau of Justice Statistics Special Report, NCJ 178247). Washington, DC: U.S. Department of Justice.

Robertson, K., \& Murachver, T. (2007). Correlates of partner violence for incarcerated women and men. Journal of Interpersonal Violence, 22, 639-655.

Steinmetz, S. K. (1977-1978). The battered husband syndrome. Victimology, 2, 499-509.

Stets, J. E., \& Straus, M. A. (1990). The marriage license as a hitting license: A comparison of assaults in dating, cohabiting, and married couples. In M. A. Straus, \& R. J. Gelles (Eds.), Physical violence in American families: Risk factors and adaptations to violence in 8,145 families (pp. 227-244). New Brunswick, NJ: Transaction Publishers.

Straus, M. A. (2008). Dominance and symmetry in partner violence by male and female university students in 32 nations. Children $\&$ Youth Services Review, 30, 252-275.

Tyler, K. A., Melander, L. A., \& Noel, H. (2009). Bidirectional partner violence among homeless young adults: Risk factors and outcomes. Journal of Interpersonal Violence, 24, 1014-1035.

Udry, J. R. (1997). User's guide to the National Longitudinal Study of Adolescent Health (Add Health), Wave I, 1994-1996. Los Altos, CA: Sociometrics.

Walker, L. E. (1979). The battered woman. New York: Harper and Row.

Weston, R., Temple, J. R., \& Marshall, L. L. (2005). Gender symmetry and asymmetry in violent relationships: Patterns of mutuality among racially diverse women. Sex Roles, 53, 553-571.

Whitaker, D. J., Haileyesus, T., Swahn, M., \& Saltzman, L. S. (2007). Differences in frequency of violence and reported injury between relationships with reciprocal and nonreciprocal intimate partner violence. American Journal of Public Health, 97, 941-947.

Whitfield, C. L., Anda, R. F., Dube, S. R., \& Felitti, V. J. (2003). Violent childhood experiences and the risk of intimate partner violence in adults: Assessment in a large health maintenance organization. Journal of Interpersonal Violence, 18, 166-185.

Williams, S., \& Frieze, I. H. (2005). Patterns of violent relationships, psychological distress, and marital satisfaction in a national sample of men and women. Sex Roles, 52, 771-784.

Zlotnick, C., Johnson, D. M., \& Kohn, R. (2006). Intimate partner violence and long-term psychosocial functioning in a national sample of American women. Journal of Interpersonal Violence, 21, 262-275.

Acknowledgments. This research uses data from Add Health, a program project designed by J. Richard Udry, Peter S. Bearman, and Kathleen Mullan Harris, and funded by a grant P01-HD31921 from the Eunice Kennedy Shriver National Institute of Child Health and Human Development, with cooperative funding from 17 other agencies. Special acknowledgment is due Ronald R. Rindfuss and Barbara Entwisle for assistance in the original design. Persons interested in obtaining data files from Add Health should contact Add Health, Carolina Population Center, 123 W. Franklin

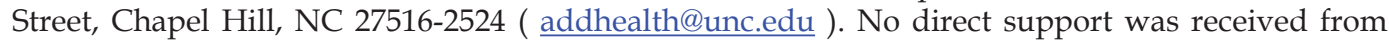
grant P01- HD31921 for this analysis. 